Research Paper

\title{
Incidence and Survival Outcomes of Breast Cancer with Synchronous Hepatic Metastases: A Population-Based Study
}

\author{
Weikai Xiao ${ }^{*}$, Shaoquan Zheng ${ }^{*}$, Anli Yang2 ${ }^{*}$, Xingcai Zhang ${ }^{3}$, Peng Liu ${ }^{1}$, Xinhua Xie ${ }^{1}$, Hailin \\ Tang ${ }^{\bowtie}$, Xiaoming Xie $\mathrm{Xi}^{\circledR}$ \\ 1. Department of Breast Oncology, Sun Yat-sen University Cancer Center, State Key Laboratory of Oncology in South China, Collaborative Innovation Center \\ for Cancer Medicine, 651 Dongfeng East Road, Guangzhou, 510060, People's Republic of China. \\ 2. Massachusetts General Hospital and Harvard Medical School, Boston, Massachusetts 02114, USA. \\ 3. Harvard John A. Paulson School of Engineering and Applied Science, Cambridge, Massachusetts 02138, USA. \\ *These authors contributed equally to this work. \\ $\square$ Corresponding authors: Xiaoming Xie , MD, PhD, Department of Breast Oncology, Sun Yat-sen University Cancer Center, State Key Laboratory of Oncology \\ in South China, Collaborative Innovation Center for Cancer Medicine, 651 Dongfeng East Road, Guangzhou, 510060, People's Republic of China (xiexm@sysucc. \\ org.cn) or Hailin Tang, MD, PhD, Department of Breast Oncology, Sun Yat-sen University Cancer Center, State Key Laboratory of Oncology in South China, \\ Collaborative Innovation Center for Cancer Medicine, 651 Dongfeng East Road, Guangzhou, 510060, People's Republic of China (tanghl@sysucc.org.cn).
}

(c) Ivyspring International Publisher. This is an open access article distributed under the terms of the Creative Commons Attribution (CC BY-NC) license (https://creativecommons.org/licenses/by-nc/4.0/). See http://ivyspring.com/terms for full terms and conditions.

Received: 2018.08.13; Accepted: 2018.08.27; Published: 2018.10.21

\begin{abstract}
Background: Little is known about the clinical features of breast cancer with synchronous hepatic metastases (BCSHM). In this retrospective study, we aimed to feature the incidence and survival outcome of BCSHM.

Methods: Data from the 2016 SEER*Stat database (version 8.3.2) was used. The effect of patient and tumor characteristics on the odds of developing of BCSHM was analyzed. Survival was investigated using Kaplan-Meier and Cox regression analyses. A competing risk model was also applied to further investigate cancer-specific survival.

Results: Of 240911 patients with breast cancer, we identified 3468 patients (1.44\%) with BCSHM. Tumor subtypes distribution of BCSHM were $45.3 \%$ HR+/HER2-, 12.2\% HR+/HER2+, 7.83\% HR-/HER2+ and $15.0 \%$ triple-negative subtype. The median OS of the entire cohort was 14 months, and only about $13.5 \%$ of patients survived at 3 years. Median survival was significantly shorter in triple-negative cohort (8 months) and gradually increased in HR+/HER2- (19 months), HR-/HER2 ${ }^{+}$(22 months) and HR+/HER2 ${ }^{+}(33$ months) cohorts $(P<0.05)$. Patients BCSHM were more likely to be young age (odds ratio [OR] 1.4, 95\% Cl 1.0-2.0), black race $(O R 1.13,95 \% \mathrm{Cl} 1.11-1.37)$, higher tumor grade (OR 3.58, 95\% Cl 2.29-5.59), unmarried status (OR 3.5, 95\% $2.1-5.7$ ), HR-/HER2+ (OR 4.07, 95\% Cl 3.56-4.67), HR+/HER2+ (OR 2.5, $95 \% \mathrm{Cl}$ 2.24-2.80) and triple-negative subtypes (OR 1.64, 95\% Cl 1.44-1.86). Poor prognostic factors were the aged (hazard ratio $3.75,95 \% \mathrm{Cl} 3.56-4.67$ ), black race (hazard ratio $1.17,95 \% \mathrm{Cl} 1.03-1.31$ ), triple-negative subtype (hazard ratio $2.23,95 \% \mathrm{Cl} 1.95-2.56$ ) and higher grade (hazard ratio $1.32,95 \% \mathrm{Cl}$ 1.03-1.68).

Conclusion: In conclusion, patients with BCSHM had a poor survival, and only $13.5 \%$ of them were alive more than 3 years. Young patients with HER2+ tumors had higher risk for developing BCSHM, but with better prognosis.
\end{abstract}

Key words: incidence, prognosis, breast cancer, synchronous hepatic metastases

\section{Introduction}

Breast cancer $(\mathrm{BC})$ is the most commonly diagnosed cancer in the world and remains the leading cause of cancer-related death in women[1, 2]. About $5-8 \%$ of BC patients develop metastatic disease 
at initial diagnosis[3, 4], and about $30 \%$ of women diagnosed with non-metastatic disease will relapse [5-7], depending on the initial stage, the biology of the tumor, and the type of treatment. The incidence of hepatic metastases ranked third in the distant metastasis, about $1-8 \%$, after bone metastases and lung metastases $[8,9]$. Distant metastasis of $\mathrm{BC}$ usually occurs later in the natural course of $B C$, most of them will be detected after a median of 3.2 years of initial cancer diagnosis[10]. Data on survival according to metastatic site in patients with a BC are absent, and as a result, specific information on survival of patients with hepatic metastases is unknown.

Breast cancer synchronous hepatic metastasis (BCSHM) is the presence of liver metastasis at initial diagnosis of breast cancer and is also known as de novo hepatic metastasis, which is different from subsequent hepatic metastasis. Population-based estimates of the incidence and prognosis of BCSHM are lacking, making the management of patients with BCSHM very challenging [11]. It is an advantage that population-based databases can provide a large number of rare clinical cases[12]. Therefore, we conducted a population-based study to determine the incidence proportions and survival outcomes of patients with BCSHM.

\section{Materials and Methods}

\section{Patients}

We extracted the data in SEER database and included patients diagnosed with invasive breast cancer from 2010 to 2014 in order to provide real representative data of recent years and sufficient follow-up time for survival analysis[13]. Patients with breast cancer in situ or unclear information about the presence of BCSHN were excluded. Subsequently, we excluded patients diagnosed by autopsy or death certificate, as well as patients without follow-up records. This study was approved by the Institutional Review Board of Sun Yat-sen University Cancer Center and written informed consent was exempted because patients cannot be identified.

Incidence was defined as the number of patients diagnosed with BCSHM divided by the total number of breast cancer patients. The incidence of BCSHM in patients with metastatic breast cancer was also calculated. In order to study the effect of tumor subtypes on the incidence and median survival of BCSHM, absolute numbers and incidence proportions of BCSHM were calculated and analyzed according to tumor type stratification. Breast cancer molecular subtypes were categorized as hormone receptor (HR) -positive/human epidermal growth factor receptor 2 (Her2)-negative, $\mathrm{HR}^{+} / \mathrm{Her} 2^{+}, \mathrm{HR}^{-} / \mathrm{HER}^{+}{ }^{+}$and triple- negative (HR negative and HER2 negative). Incidence proportions were also calculated after stratification by race, sex, age at diagnosis, pathological grade, etc. According to the SEER database, the race was classified as white, black, Asian or Pacific Islander, and American Indian/Alaska Native.

\section{Statistical analysis}

Multivariate logistic regression was used to determine whether age, sex, and race are associated with the presence of BCSHM at cancer diagnosis; other variables in the model include marital status, insurance status, pathological grade, molecular subtype, and extrahepatic metastases. The presence of bone, lung and brain metastases at diagnosis can be obtained in the SEER database and used to characterize the degree of systemic disease in the patient in this study. The Kaplan-Meier method was used to calculate the survival estimate. Multivariate Cox regression was performed using the same variables as the logistic regression model mentioned above to identify covariates associated with increased all-cause mortality. Statistical analysis was performed using SPSS statistical software (SPSS IBM STATISTICS 21), apart from the Kaplan-Meier curve by SAS 9.4 software (SAS Institute, Cary, NC) and breast cancer-specific mortality using a competing risk analysis model by cmprsk package of $\mathrm{R}$ software (version 3.4.1).

\section{Results}

\section{Incidence of BCSHM}

In the SEER database, we identified 240,911 patients aged 20 years or older diagnosed with primary invasive breast cancer between January 1, 2010, and December 31, 2014. The distribution of $\mathrm{HR}^{+} / \mathrm{HER} 2^{-}, \mathrm{HR}^{+} / \mathrm{HER}^{+}{ }^{+}$HR-/HER2 ${ }^{+}$, triplenegative and unknown subtypes was $67.7 \%, 9.33 \%$, $4.09 \%, 10.7 \%$ and $8.27 \%$, respectively, among the entire cohort. The proportion of $\mathrm{HR}^{+} / \mathrm{HER} 2$-, $\mathrm{HR}^{+} / \mathrm{HER} 2^{+}$, $\mathrm{HR}^{-} / \mathrm{HER}^{+}{ }^{+}$triple-negative and unknown subtypes was $51.3 \%, 13.0 \%, 7.11 \%, 11.8 \%$ $16.9 \%$, respectively, in the cohort of metastatic breast cancer $(n=13,426)$. The tumor subtype distribution of BCSHM was $45.3 \%$ HR-/HER2-, $12.2 \% \mathrm{HR}^{+} / \mathrm{HER}^{+}{ }^{+}$, $7.83 \% \mathrm{HR}^{-} / \mathrm{HER}^{+}{ }^{+}$and $15.0 \%$ triple-negative subtype. The number and incidence of BCSHM at the initial diagnosis of breast cancer are shown in Table 1, stratified by tumor subtype.

In the entire cohort, 3468 patients with BCSHM, reflecting the incidence of BCSHM, accounted for $1.44 \%$ of the all patients with BC, and $25.8 \%$ of the subgroup of metastatic diseases.

On multivariable logistic regression (Table 2) among patients with metastatic cancer, age 40 to 59 
years (vs age 20 to 39 years; OR, 0.74; 95\% CI, 0.64-0.86; $\mathrm{P}<.001$ ), age 60 to 79 years (vs age 20 to 39 years; OR, $0.62 ; 95 \% \mathrm{CI}, 0.53-0.72 ; \mathrm{P}<.001$ ), age $\geq 80$ years (vs age 20 to 39 years; OR, 0.55 ; $95 \% \mathrm{CI}, 0.46-0.67$; $\mathrm{P}<.001)$; black women(vs white women; OR, 1.13; 95\% CI, 1.11-1.37; $\mathrm{P}<.001$ ); the presence of brain metastasis(vs no; $\mathrm{OR}$, 2.40; 95\% CI, 2.01-2.86; $\mathrm{P}<.001$ ) and lung metastasis(vs no; OR, 5.58; 95\%CI, 5.03-6.18; $\mathrm{P}<.001) ; \mathrm{HR}^{+} / \mathrm{HER}^{+}$ (vs $\mathrm{HR}^{+}$/HER2-; OR, 2.50; 95\%CI, 2.24-2.80; $\mathrm{P}<.001$ ), $\mathrm{HR}^{-} / \mathrm{HER}^{+}{ }^{+}$(vs $\mathrm{HR}^{+} / \mathrm{HER} 2 ; \mathrm{OR}, 4.07 ; 95 \% \mathrm{CI}$, 3.56-4.67; $\mathrm{P}<.001$ ), and triple-negative subtypes (vs $\mathrm{HR}^{+}$/HER2; OR, 1.64; 95\% CI, 1.44-1.86; P<.001) were associated with significantly greater odds of having BCSHM at diagnosis. Insured status was associated with significantly lower odds of hepatic metastasis at diagnosis (OR, 0.76; 95\% CI, 0.63-0.92; $\mathrm{P}=.004)$.

\section{Survival}

Breast cancer patients with an initial diagnosis of BCSHM with an active follow-up $(\mathrm{n}=3021)$ were included in survival data analysis. The median OS of the entire cohort was 14 months, and only about $13.5 \%$ of patients survived at 3 years. Among them, the median survival time was the longest (31.0 months) and the shortest (8.0 months) in the patients with HR+/HER2+ subtype and triple-negative subtype, respectively. Overall survival (Figure 1, A), survival stratified by subtype (Figure 1, B), hepatic metastases status (Figure 1, C) and the extent of metastatic diseases (Figure 1, D) were shown in Figure 1. Multivariate analysis of all-cause death in patients with BCSHM at diagnosis (Table 3 ), age 40 to 59 years (vs age $20-39$ years; hazard ratio, $1.34 ; 95 \% C I$, 1.10-1.63; $P=.004$ ), age 60 to 79 years (vs age 20-39 years; hazard ratio, $1.91 ; 95 \% C I, 1.57-2.33 ; P<.001)$, and age greater than 80 years (vs age 20-39 years; hazard ratio, 3.75; 95\% CI, 3.00-4.72; $P<.001$ ), black race (vs white; hazard ratio, $1.17 ; 95 \% C I, 1.03-1.31 ; P$ $=.013$ ), metastatic diseases to 1 extrahepatic sites (vs 0 site; hazard ratio,1.27; 95\%CI, 1.13-1.43; $P<.001), 2$ extrahepatic sites (vs 0 site; hazard ratio, $1.69 ; 95 \% \mathrm{CI}$, 1.48-1.92; $P<.001$ ), 3 extrahepatic sites (vs 0 site; hazard ratio, 2.28; 95\% CI, 1.82-2.85; $P<.001)$, triple-negative (vs $\mathrm{HR}^{+}$/HER2-; hazard ratio, 2.23; 95\% CI, 1.95-2.56; $P<.001$ ) and pathological grade III(vs grade I; hazard ratio,1.32; 95\% CI, 1.03-1.68; $P=0.027$ ) were significantly associated with an increased all-cause mortality.

$\mathrm{HR}^{+} / \mathrm{HER}^{+}{ }^{+}$(vs HR+ ${ }^{+}$HER2-; hazard ratio, 0.70; 95\% CI, 0.61-0.81; P<.001), married status (vs unmarried status; hazard ratio, $0.82 ; 95 \% C I, 0.75-0.91$; $P<.001$ ), and insured status (vs uninsured status; hazard ratio, $0.73 ; 95 \% C I, 0.58-0.91 ; P=.004$ ) were significantly associated with a decreased all-cause mortality.
Breast cancer-specific mortality in patients with BCSHM among newly diagnosed breast cancer was also shown in Table 3. Table 4 showed the median survival of subclasses that are stratified by site of extrahepatic metastasis. In general, the median survival of patients involved in more extrahepatic metastases was poor. We also found that the presence of BCSHM at the time of initial diagnosis was associated with shorter survival time compared with patients with metastatic diseases without liver involvement (Table 4).

\section{Discussion}

To the best of our knowledge, the current study is by far the largest study for assessing the incidence and prognosis for de novo liver metastasis from breast cancer. In this large cohort study, data from 240911 breast cancer were analyzed, and we identified 3468 patients with de novo live metastasis, accounting for $1.44 \%$ of all breast cancer patients. Higher BCSHM Incidence proportions were among patients with younger age, black race, HER2 ${ }^{+}$subtypes, triple negative subtypes, unmarried status, uninsured status, higher pathological grade. The presence of BCSHM has a negative effect on the prognosis of patients and the survival of patients with BCSHM is subtype-dependent.

It was reported that the incidence of BCSHM among metastatic BC varied from $20 \%$ to $35 \%[14,15]$. The incidence of BCSHM among subgroup with metastatic diseases was $25.8 \%$ in this study, consistent with the previously reported results. Almost half of all BCSHM were $\mathrm{HR}^{+} / \mathrm{HER} 2-$ tumors. As patients with $\mathrm{HR}^{+} / \mathrm{HER} 2-$ tumors accounted for approximately two-thirds of all $\mathrm{BC}$ patients, the odds of developing of BCSHM of $\mathrm{HR}^{+} / \mathrm{HER} 2$ - tumors is lower than other subtypes. In this study, patients with HR-/ $\mathrm{HER}^{+}$and $\mathrm{HR}^{+} / \mathrm{HER}^{+}{ }^{+}$tumors were most often diagnosed with synchronous hepatic metastases $(4.24 \%$ and $2.78 \%$ of patients had BCSHM). In addition, in the subgroup of metastatic disease, most of these patients had BCSHM (43.8\% and 35.8\%). To date, previous studies have explored patterns of recurrence and metastasis of breast cancer subtypes. Our study is the first large-scale study to specially explore BCSHM and tumor subtypes. Interestingly, the direction of association between hepatic metastasis and subtype is similar in our study of BCSHM and previous studies of recurrent hepatic metastasis: hepatic metastasis including BCSHM and liver relapse is particularly higher in HER2+ subtypes $[6,16]$.

Few studies specifically describe which patients are more likely to have BSHHM. In addition to the tumor subtype, younger age, black race, unmarried 
status, uninsured status, and higher pathological grade are relevant factors for the developing of BCSHM in this study and were described earlier as relevant factors for advanced disease[17-21]. Some

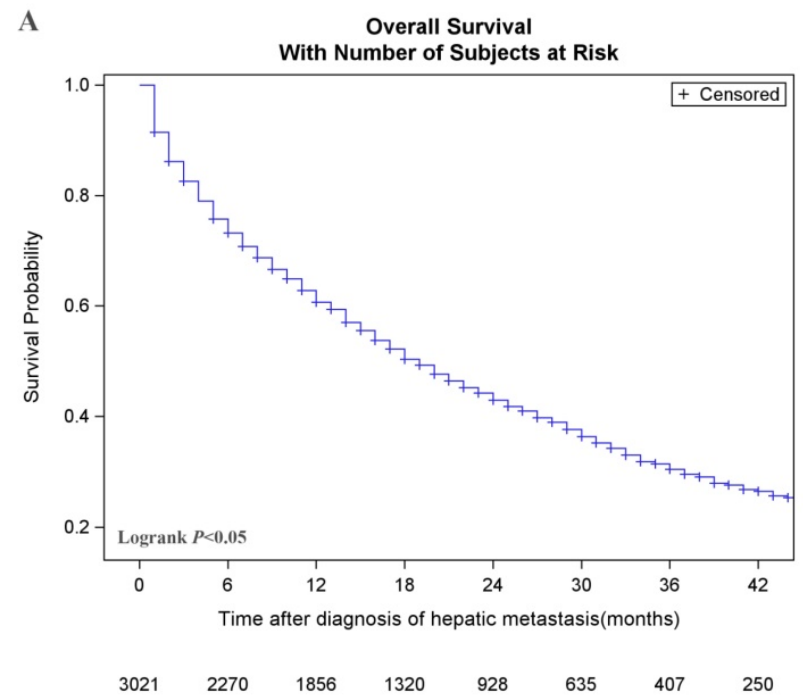

C Survival Stratified by Hepatic Metastatic Status

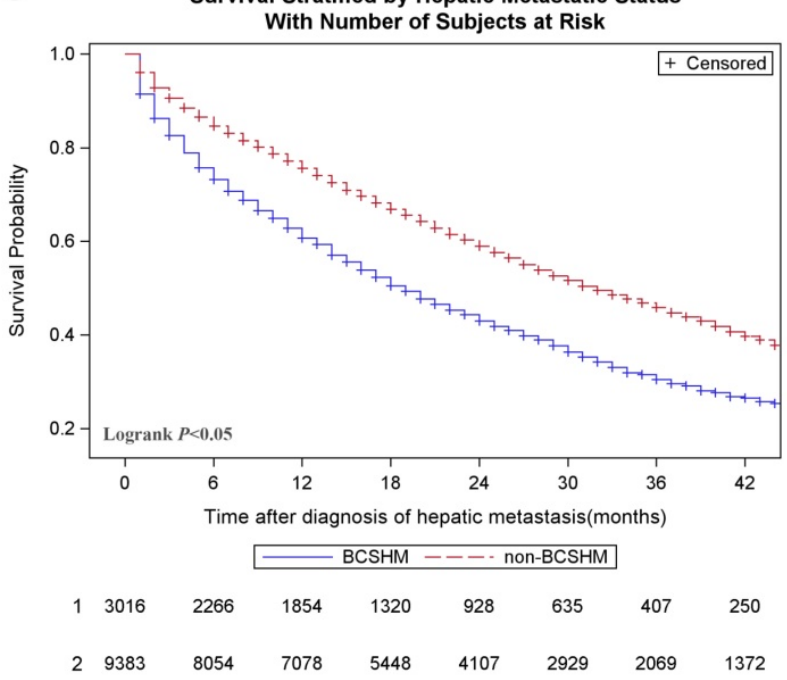

studies also describe possible genetic changes as relevant factors for distant metastasis of $\mathrm{BCs}$ [22]. Unfortunately, data on genetics and $\mathrm{Ki}-67 \%$ are not yet available in our study[18].

B

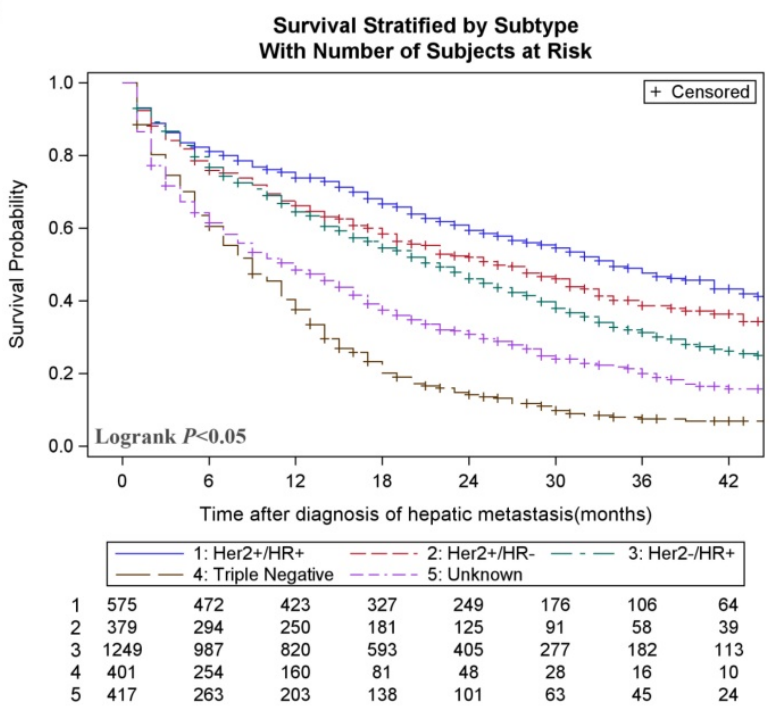

D Survival Stratified by the Extent of Extrahepatic Metastatic Diseases With Number of Subjects at Risk

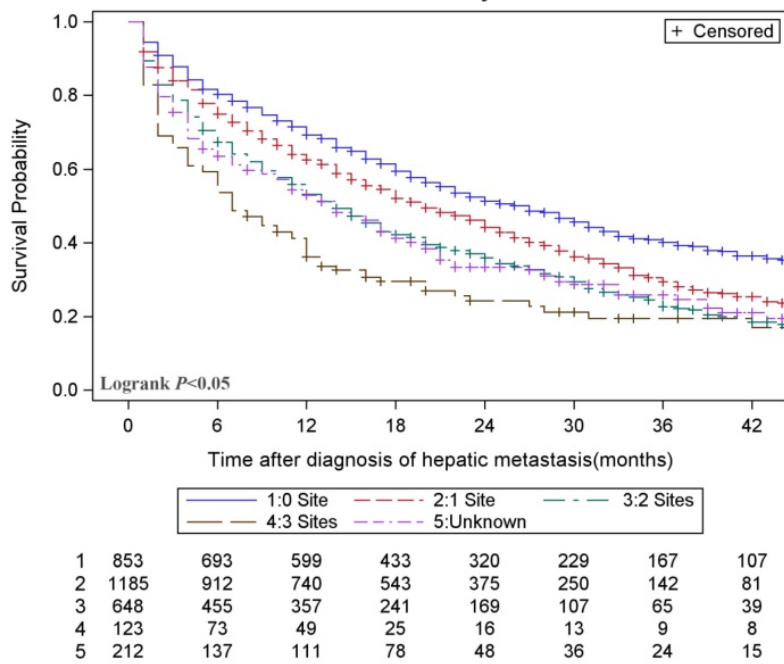

Figure 1. Kaplan-Meier curves of survival among patients with hepatic metastases at the initial diagnosis of breast cancer. A. Overall survival of patients with BCSHM. B. Survival curves stratified by different molecular subtypes. C. Survival curves stratified by BCSHM and non-BCSHM among metastatic diseases. D. Survival stratified by the extent of extrahepatic metastatic diseases which is classified by the number of metastatic sites to the bone, lung, or brain. HER2, human epidermal growth factor receptor 2; HR, hormone receptor. + Denotes positive; - denotes negative.

Table 1. The incidence and median survival of patients with BCSHM were stratified by subtypes

\begin{tabular}{|c|c|c|c|c|c|c|}
\hline \multirow[b]{2}{*}{ Subtype } & \multicolumn{3}{|l|}{ Patients, No. } & \multicolumn{2}{|c|}{ Incidence Proportion of hepatic metastasis, $\%$} & \multirow[b]{2}{*}{$\begin{array}{l}\text { Median Survival of } \\
\text { BCSHM (IQR), months }\end{array}$} \\
\hline & $\begin{array}{l}\text { With breast } \\
\text { Cancer }\end{array}$ & $\begin{array}{l}\text { With Metastatic } \\
\text { Diseases }\end{array}$ & BCSHM & $\begin{array}{l}\text { Among Entire } \\
\text { Cohort }\end{array}$ & $\begin{array}{l}\text { Among Subgroup with } \\
\text { Metastatic Diseases }\end{array}$ & \\
\hline $\mathrm{HR}^{+} / \mathrm{HER} 2-$ & 163001 & 6883 & 1355 & 0.83 & 19.7 & $19(5.0-41.0)$ \\
\hline $\mathrm{HR}^{+} / \mathrm{HER}^{+}{ }^{+}$ & 22478 & 1745 & 624 & 2.78 & 35.8 & $31(6.0-\mathrm{NR})$ \\
\hline HR-/HER2 ${ }^{+}$ & 9850 & 955 & 418 & 4.24 & 43.8 & $22(4.0-47.0)$ \\
\hline Triple-negative & 25647 & 1579 & 437 & 1.70 & 27.7 & $8(2.0-15.0)$ \\
\hline Unknown & 19935 & 2264 & 634 & 3.18 & 28.0 & $3(0-19.0)$ \\
\hline All subtypes & 240911 & 13426 & 3468 & 1.44 & 25.8 & $14(3.0-39.0)$ \\
\hline
\end{tabular}

Abbreviations: BCSHM, breast cancer with synchronous hepatic metastases; HER2, human epidermal growth factor receptor 2; HR, hormone receptor; IQR, interquartile range; NR, not reached. + Denotes positive; - denotes negative. 
Table 2. Multivariate logistic regression of hepatic metastases at the initial diagnosis of breast cancer

\begin{tabular}{|c|c|c|c|c|c|c|}
\hline \multirow[b]{2}{*}{ Variable } & \multicolumn{2}{|l|}{ Patients, No } & \multicolumn{2}{|c|}{ Among Entire Corhort } & \multicolumn{2}{|c|}{ Among Subset With Metastatic Diseases } \\
\hline & Patients (n=240892) & BCSHM (n=3468) & OR(95\%CI) & $P$ & OR(95\%CI) & $P$ \\
\hline \multicolumn{7}{|l|}{ Age at diagnosis, $\mathrm{y}^{\mathrm{a}}$} \\
\hline $20-39$ & 11219 & 277 & 1(Reference) & & 1(Reference) & \\
\hline $40-59$ & 95136 & 1464 & $0.74(0.64-0.86)$ & $<.001$ & $0.78(0.66-0.92)$ & 0.003 \\
\hline $60-79$ & 107737 & 1369 & $0.62(0.53-0.72)$ & $<.001$ & $0.61(0.52-0.72)$ & $<.001$ \\
\hline$\geq 80$ & 26800 & 358 & $0.55(0.46-0.67)$ & $<.001$ & $0.48(0.39-0.58)$ & $<.001$ \\
\hline \multicolumn{7}{|l|}{ Sex } \\
\hline Female & 239014 & 3447 & 1(Reference) & & 1(Reference) & \\
\hline Male & 1878 & 21 & $0.45(0.27-0.74)$ & 0.002 & $0.45(0.28-0.73)$ & .001 \\
\hline \multicolumn{7}{|l|}{ Race } \\
\hline White & 191861 & 2585 & 1(Reference) & & 1(Reference) & \\
\hline Black & 26620 & 624 & 1.13(1.11-1.37) & $<.001$ & $1.01(0.90-1.12)$ & 0.924 \\
\hline Asian or Pacific Islander & 19485 & 226 & $0.93(0.56-1.55)$ & 0.79 & $0.88(0.52-1.49)$ & 0.631 \\
\hline $\begin{array}{l}\text { American Indian/ } \\
\text { Alaska Native }\end{array}$ & 1371 & 20 & $0.85(0.73-0.99)$ & 0.038 & $0.94(0.80-1.11)$ & 0.471 \\
\hline Unknown & 1555 & 13 & $0.68(0.37-1.25)$ & 0.211 & $0.83(0.44-1.59)$ & 0.578 \\
\hline \multicolumn{7}{|l|}{ Marital status } \\
\hline Unmarried & 98187 & 1759 & 1(Reference) & & 1(Reference) & \\
\hline Married & 128724 & 1494 & $0.88(0.81-0.96)$ & 0.003 & $1.03(0.95-1.12)$ & 0.508 \\
\hline Unknown & 13981 & 215 & $1.02(1.02-1.21)$ & 0.80 & $1.15(0.96-1.37)$ & 0.127 \\
\hline \multicolumn{7}{|l|}{ Insurance status } \\
\hline Uninsured & 4495 & 195 & 1(Reference) & & 1(Reference) & \\
\hline Insured & 231450 & 3186 & $0.76(0.63-0.92)$ & 0.004 & $0.74(0.62-0.88)$ & .001 \\
\hline Unknown & 4947 & 87 & $0.74(0.54-1.02)$ & 0.067 & $0.80(0.59-1.08)$ & 0.142 \\
\hline \multicolumn{7}{|l|}{ Brain Met } \\
\hline $\mathrm{NO}$ & 239636 & 2976 & 1(Reference) & & 1(reference) & \\
\hline Yes & 963 & 322 & $2.40(2.01-2.86)$ & $<.001$ & $1.33(1.15-1.54)$ & $<.001$ \\
\hline Unknown & 293 & 170 & $3.60(2.63-4.93)$ & $<.001$ & $3.38(2.54-4.50)$ & $<.001$ \\
\hline \multicolumn{7}{|l|}{ Bone Met } \\
\hline NO & 232064 & 1343 & 1(Reference) & & 1(reference) & \\
\hline Yes & 8617 & 2036 & 21.42(19.58-23.44) & $<.001$ & $0.83(0.77-0.91)$ & $<.001$ \\
\hline Unknown & 211 & 89 & $17.80(12.23-25.92)$ & $<.001$ & $1.96(1.31-2.93)$ & .001 \\
\hline \multicolumn{7}{|l|}{ Lung Met } \\
\hline NO & 236423 & 2099 & 1(Reference) & & 1(reference) & \\
\hline Yes & 4085 & 1207 & $5.58(5.03-6.18)$ & $<.001$ & $1.30(1.19-1.42)$ & $<.001$ \\
\hline Unknown & 384 & 162 & $6.31(4.78-8.32)$ & $<.001$ & $2.52(1.94-3.26)$ & $<.001$ \\
\hline \multicolumn{7}{|l|}{ Subtype } \\
\hline $\mathrm{HR}^{+} / \mathrm{HER} 2-$ & 162997 & 1355 & 1(Reference) & & 1(Reference) & \\
\hline $\mathrm{HR}^{+} / \mathrm{HER}^{+}{ }^{+}$ & 22477 & 624 & $2.50(2.24-2.80)$ & $<.001$ & $2.04(1.81-2.30)$ & $<.001$ \\
\hline $\mathrm{HR}^{-} / \mathrm{HER} 2^{+}$ & 9849 & 418 & $4.07(3.56-4.67)$ & $<.001$ & $2.63(2.27-3.04)$ & $<.001$ \\
\hline Triple-negative & 25645 & 437 & $1.64(1.44-1.86)$ & $<.001$ & $1.29(1.13-1.48)$ & $<.001$ \\
\hline Unknown & 19924 & 634 & $1.78(1.57-2.01)$ & $<.001$ & $1.46(1.29-1.65)$ & $<.001$ \\
\hline \multicolumn{7}{|l|}{ Pathological Grade } \\
\hline 1 & 51551 & 139 & 1(Reference) & & 1(Reference) & \\
\hline 2 & 99005 & 938 & $1.96(1.62-2.3)$ & $<.001$ & $1.23(1.01-1.51)$ & 0.042 \\
\hline 3 & 73260 & 1447 & $2.98(2.47-3.60)$ & $<.001$ & $1.47(1.20-1.80)$ & $<.001$ \\
\hline 4 & 1105 & 32 & $3.58(2.29-5.59)$ & $<.001$ & $1.16(0.72-1.85)$ & 0.544 \\
\hline unknown & 15971 & 912 & $4.11(3.37-5.01)$ & $<.001$ & $1.39(1.13-1.71)$ & 0.002 \\
\hline
\end{tabular}

Table 3. Multivariate cox regression of all-cause mortality and specific breast cancer mortality in patients with hepatic metastasis

\begin{tabular}{|c|c|c|c|c|c|c|}
\hline \multirow[b]{2}{*}{ Variables } & \multicolumn{2}{|l|}{ Patients, No } & \multicolumn{2}{|c|}{ All-Cause Mortality } & \multicolumn{2}{|c|}{ Breast cancer-special mortality } \\
\hline & $\begin{array}{l}\text { Patients } \\
(n=238834)\end{array}$ & $\begin{array}{l}\text { With BCSHM } \\
(n=3021)\end{array}$ & OR(95\%CI) & P Value & $\mathrm{HR}(95 \% \mathrm{CI})$ & P Value \\
\hline \multicolumn{7}{|c|}{ Age at diagnosis, $\mathrm{y}^{\mathrm{a}}$} \\
\hline $20-39$ & 11184 & 261 & 1(Reference) & & 1(Reference) & \\
\hline $40-59$ & 94562 & 1317 & $1.34(1.10-1.63)$ & 0.004 & $1.26(1.04-1.52)$ & 0.019 \\
\hline $60-79$ & 106851 & 1167 & $1.91(1.57-2.33)$ & $<.001$ & $1.37(1.13-1.67)$ & .0016 \\
\hline$\geq 80$ & 26237 & 276 & $3.75(3.00-4.72)$ & $<.001$ & $1.79(1.39-2.30)$ & $<.001$ \\
\hline \multicolumn{7}{|l|}{ Sex } \\
\hline Female & 236980 & 3003 & 1(Reference) & & 1(Reference) & \\
\hline Male & 1854 & 18 & $0.80(0.44-1.46)$ & 0.463 & $1.33(0.59-2.98)$ & 0.49 \\
\hline Race & & & & & & \\
\hline
\end{tabular}




\begin{tabular}{|c|c|c|c|c|c|c|}
\hline \multirow[b]{2}{*}{ Variables } & \multicolumn{2}{|l|}{ Patients, No } & \multicolumn{2}{|c|}{ All-Cause Mortality } & \multicolumn{2}{|c|}{ Breast cancer-special mortality } \\
\hline & $\begin{array}{l}\text { Patients } \\
(n=238834)\end{array}$ & $\begin{array}{l}\text { With BCSHM } \\
(\mathrm{n}=3021)\end{array}$ & OR(95\%CI) & P Value & HR(95\%CI) & P Value \\
\hline White & 190394 & 2271 & 1(Reference) & & 1(Reference) & \\
\hline Black & 26351 & 522 & $1.17(1.03-1.31)$ & 0.013 & $1.07(0.94-1.23)$ & 0.31 \\
\hline Asian or Pacific Islander & 1361 & 19 & $1.07(0.89-1.29)$ & 0.466 & $1.11(0.90-1.36)$ & 0.32 \\
\hline $\begin{array}{l}\text { American Indian/ } \\
\text { Alaska Native }\end{array}$ & 19305 & 198 & $0.96(0.54-1.70)$ & 0.900 & $0.94(0.48-1.86)$ & 0.86 \\
\hline Unknown & 1423 & 11 & $0.58(0.24-1.42)$ & 0.234 & $0.89(0.39-2.02)$ & 0.78 \\
\hline \multicolumn{7}{|l|}{ Marital status } \\
\hline Unmarried & 97134 & 1496 & 1(Reference) & & 1(Reference) & \\
\hline Married & 128047 & 1352 & $0.82(0.75-0.91)$ & $<.001$ & $0.93(0.84-1.04)$ & 0.19 \\
\hline Unknown & 13653 & 173 & $0.94(0.76-1.15)$ & 0.522 & $1.10(0.88-1.36)$ & 0.41 \\
\hline \multicolumn{7}{|l|}{ Insurance status } \\
\hline Uninsured & 4345 & 131 & 1(Reference) & & 1(Reference) & \\
\hline Insured & 229813 & 2820 & $0.73(0.58-0.91)$ & 0.004 & $0.73(0.57-0.93)$ & 0.012 \\
\hline Unknown & 4676 & 70 & $0.72(0.50-1.06)$ & 0.093 & $0.59(0.38-0.92)$ & 0.021 \\
\hline \multicolumn{7}{|c|}{ Extrahepatic metastatic sites to bone,brain and lung } \\
\hline 0 & 228729 & 853 & 1(reference) & & 1(Reference) & \\
\hline 1 & 7147 & 1185 & $1.27(1.13-1.43)$ & $<.001$ & $1.45(1.27-1.65)$ & $<.001$ \\
\hline 2 & 2117 & 648 & $1.69(1.48-1.92)$ & $<.001$ & $1.75(1.50-2.03)$ & $<.001$ \\
\hline 3 & 253 & 123 & $2.28(1.82-2.85)$ & $<.001$ & $2.29(1.74-3.01)$ & $<.001$ \\
\hline Unknown & 588 & 212 & $1.58(1.31-1.90)$ & $<.001$ & $1.83(1.48-2.27)$ & $<.001$ \\
\hline \multicolumn{7}{|l|}{ Subtype } \\
\hline $\mathrm{HR}^{+} / \mathrm{HER} 2-$ & 162184 & 1249 & 1(Reference) & & 1(Reference) & \\
\hline $\mathrm{HR}^{+} / \mathrm{HER}^{+}{ }^{+}$ & 22336 & 575 & $0.70(0.61-0.81)$ & $<.001$ & $0.77(0.66-0.90)$ & .0013 \\
\hline HR-/HER2+ & 9767 & 379 & $0.98(0.82-1.15)$ & 0.816 & $0.95(0.80-1.12)$ & 0.54 \\
\hline Triple-negative & 25475 & 401 & $2.23(1.95-2.56)$ & $<.001$ & $1.78(1.52-2.08)$ & $<.001$ \\
\hline Unknown & 19072 & 417 & $1.39(1.20-1.59)$ & $<.001$ & $1.35(1.16-1.59)$ & $<.001$ \\
\hline \multicolumn{7}{|l|}{ Pathological Grade } \\
\hline 1 & 51319 & 132 & 1(Reference) & & 1(Reference) & \\
\hline 2 & 98454 & 846 & $1.06(0.83-1.35)$ & 0.65 & $1.29(0.96-1.74)$ & 0.093 \\
\hline 3 & 72756 & 1326 & $1.32(1.03-1.68)$ & 0.027 & $1.54(1.15-2.07)$ & 0.0041 \\
\hline 4 & 1087 & 28 & $1.34(0.81-2.22)$ & 0.263 & $1.70(0.94-3.09)$ & 0.081 \\
\hline unknown & 15218 & 689 & $1.26(0.98-1.62)$ & 0.075 & $1.49(1.09-2.01)$ & 0.01 \\
\hline
\end{tabular}

The median survival after BCSHM diagnosis was 14 months, but significant differences were found based on tumor subtypes. $\mathrm{HR}^{+} / \mathrm{HER}^{+}$patients had the longest survival time (median survival, 31.0 months), and triple-negative breast cancer was associated with the worst survival (median survival, 8.0 Month). We found that $\mathrm{HR}^{+} / \mathrm{HER}^{+}$subtype BCSHM patients had a better survival rate than $\mathrm{HR}^{+}$/ HER2- subtype, whereas HR-/ HER2 ${ }^{+}$subtype had better survival rates than triple negative subtype. This difference may be due to the introduction of HER2-targeted therapy because all patients in our study were diagnosed after 2010. Previous studies have demonstrated the efficacy of trastuzumab in metastatic breast cancer[23-25]. In agreement with previous studies[26, 27], triple negative breast cancer had the worst prognosis, and in our BCSHM subgroup this phenomenon remained. Hopefully, new therapies, including PARP inhibitors and immunotherapy, have been shown to improve the survival of triple-negative breast cancers, but further research is needed if these new therapies can improve the prognosis of triple-negative BCSHM[28, 29].
One notable finding is that although elderly patients have a lower risk of developing BCSHM than younger patients, the prognosis of elderly with BCSHM is significantly worse than in younger patients. The possible cause of our results was that older patients tend to have poor adherence to standard treatment regimens compared with young patients, and inadequate treatment may lead to higher mortality rates. Another possibility is that older patients with BCSHM may be have some severe comorbidities that affect their ability to fully benefit from the treatment or fail to accept some treatments with serious side effects[30].

Interestingly, married patients are less likely to have BCSHM than unmarried women and have a lower risk of breast-related death. In addition, the lack of health insurance increases the incidence of BCSHM and the risk of death. These indicated that marital status and insurance status may affect how cancer patients get access to health services. It is conceivable that both unmarried and low-income patients have a more vulnerable support network, which may have contributed to the detection of their tumor only after it 
had metastasized. On the other hand, these factors may in turn affect access to advanced therapies and adequate diseases management. In fact, although the treatment of $\mathrm{BC}$ is becoming more effective, it also becomes more complicated and expensive at the same time. Some new drugs, such as monoclonal antibodies, immunomodulators and proteasome inhibitors, have recently been approved for advanced breast cancer and may further increase the cost of treatment and exacerbate these differences[31].

Table 4. The Median Survival of Patients with Breast Cancer Stratified by Sites of Metastases.

\begin{tabular}{|c|c|c|c|}
\hline \multirow[b]{2}{*}{ Subtype } & \multirow{2}{*}{$\begin{array}{l}\text { Type of } \\
\text { metastasis }\end{array}$} & \multicolumn{2}{|c|}{ Survival, median (IQR), months } \\
\hline & & Without BCSHM & With BCSHM \\
\hline \multirow[t]{5}{*}{$\mathrm{HR}^{+} / \mathrm{HER}^{-}$} & Bone & $37(35.5-38.5)$ & $21(18.7-23.3)$ \\
\hline & Lung & $31(28.1-33.9)$ & $17(12.9-21.1)$ \\
\hline & Brain & $16(11.8-20.2)$ & $13(8.2-17.8)$ \\
\hline & 2 of 3 & $28(25.5-30.5)$ & $15(11.5-18.5)$ \\
\hline & All 3 & $25(16.3-33.7)$ & $16(3.0-29.0)$ \\
\hline \multirow[t]{5}{*}{$\mathrm{HR}^{+} / \mathrm{HER}^{+}{ }^{+}$} & Bone & $46(42.2-49.8)$ & $30(24.8-35.2)$ \\
\hline & Lung & $40(33.3-46.7)$ & $22(16.2-27.8)$ \\
\hline & Brain & $30(17.7-42.3)$ & $15(0-34.3)$ \\
\hline & 2 of 3 & $39(32.4-45.6)$ & $22(15.6-28.4)$ \\
\hline & All 3 & $17(6.0-30.0)$ & $9(4.6-13.4)$ \\
\hline \multirow[t]{5}{*}{$\mathrm{HR}^{-} / \mathrm{HER}^{+}{ }^{+}$} & Bone & $34(21.3-46.7)$ & $21(16.2-25.8)$ \\
\hline & Lung & $23(19.1-26.9)$ & $16(11.2-20.8)$ \\
\hline & Brain & $14(8.6-19.4)$ & $6(2.9-9.1)$ \\
\hline & 2 of 3 & $17(10.6-23.4)$ & $18(11.4-24.6)$ \\
\hline & All 3 & $9(0.4-17.6)$ & $5(1.1-8.9)$ \\
\hline \multirow[t]{5}{*}{ Triple-negative } & Bone & $12(10.7-13.3)$ & $7(6.0-8.00)$ \\
\hline & Lung & $12(10.7-13.3)$ & $7(4.9-9.1)$ \\
\hline & Brain & $7(4.6-9.4)$ & $5(1.9-8.1)$ \\
\hline & 2 of 3 & $9(7.1-10.9)$ & $5(3.0-7.0)$ \\
\hline & All 3 & $4(2.4-5.6)$ & $4(0-9.0)$ \\
\hline \multirow[t]{5}{*}{ Unknown } & Bone & $21(18.0-24.0)$ & $11(7.5-14.5)$ \\
\hline & Lung & $14(10.8-17.2)$ & $8(3.6-12.4)$ \\
\hline & Brain & $6(2.7-9.3)$ & $2(0.4-3.7)$ \\
\hline & 2 of 3 & $14(10.7-17.3)$ & $12(6.4-17.6)$ \\
\hline & All 3 & $12(0-29.7)$ & $2(1.3-2.7)$ \\
\hline \multirow[t]{5}{*}{ All subtypes } & Bone & $34(32.7-35.3)$ & $18(16.5-19.5)$ \\
\hline & Lung & $24(22.5-25.5)$ & $14(12.4-15.6)$ \\
\hline & Brain & $13(10.8-15.2)$ & $9(6.8-11.2)$ \\
\hline & 2 of 3 & $24(22.0-26.0)$ & $14(12.17-15.83)$ \\
\hline & All 3 & $14(9.9-22.1)$ & $7(4.59-9.41)$ \\
\hline
\end{tabular}

Abbreviations: BCSHM, breast cancer with synchronous hepatic metastases; HER2, human epidermal growth factor receptor 2; HR, hormone receptor; IQR,

interquartile range; + Denotes positive; - denotes negative.

Our research also involves several implications for future clinical research and practice. First, special attention should be paid to the socio-demographic factors that increase the incidence and mortality of BCSHM. Our results show that black ethnicity, unmarried status, and uninsured status have a relatively higher risk of developing hepatic metastases and a high risk of death. In designing randomized controlled studies, researchers should pay attention to adjusting these confounding factors. Second, patients with unknown molecular typing have a higher risk of BCSHM and poorer survival and also indicating the important role of molecular type in guiding therapies. Unlike previous studies, our results show that younger patients with BCSHM have a better prognosis. Future research is needed to further evaluate and optimize the treatment and management of elderly patients with metastatic breast cancer.

We also acknowledge that this study is limited by its inherent nature. First, since the SEER database does not provide information on the number and size of hepatic metastases, we can not analyze the impact of the size and number of metastases on the prognosis of patients. Future research based on more complete databases should be used to address this important issue. Second, we were unable to evaluate the effect of treatment on the prognosis of patients with BCSHM, since information about liver surgery, endocrine therapy, and HER2-targeted therapy was not recorded in the SEER database, which may help to analyze some of the differences observed in survival based on prognostic variables. Finally, we were not able to analyze other important factors such as performance status, BMI index, and smoking status that may affect morbidity or prognosis because the SEER database did not provide these data.

\section{Conclusions}

In conclusion, about $1.43 \%$ of $\mathrm{BC}$ patients have BCSHM. The incidence and prognosis of BCSHM vary with age, ethnicity, and subtype. Young patients with HER2 $^{+}$tumors had higher risk for developing BCSHM, but with better prognosis. Advanced age and triple-negative subtype predict worse prognosis. Low socioeconomic status is associated with an increased risk of hepatic metastases and worse prognosis.

\section{Acknowledgements}

This study was supported by the National Natural Science Foundation of China (81672598, 81772961).

\section{Competing Interests}

The authors have declared that no competing interest exists.

\section{References}

1. Miller KD, Siegel RL, Lin CC, Mariotto AB, Kramer JL, Rowland JH, et al. Cancer treatment and survivorship statistics, 2016. CA Cancer J Clin. 2016; 66: 271-89.

2. Ginsburg O, Bray F, Coleman MP, Vanderpuye V, Eniu A, Kotha SR, et al. The global burden of women's cancers: a grand challenge in global health. Lancet. 2017; 389: 847-60.

3. DeSantis CE, Fedewa SA, Goding SA, Kramer JL, Smith RA, Jemal A. Breast cancer statistics, 2015: Convergence of incidence rates between black and white women. CA Cancer J Clin. 2016; 66: 31-42.

4. Leone BA, Vallejo CT, Romero AO, Machiavelli MR, Pérez JE, Leone J, et al. Prognostic impact of metastatic pattern in stage IV breast cancer at initial diagnosis. Breast Cancer Res Treat. 2017; 161: 537-48.

5. Redig AJ, McAllister SS. Breast cancer as a systemic disease: a view of metastasis. J Intern Med. 2013; 274: 113-26. 
6. Kennecke H, Yerushalmi R, Woods R, Cheang MC, Voduc D, Speers CH, et al. Metastatic behavior of breast cancer subtypes. J Clin Oncol. 2010; 28: 3271-7.

7. Berman AT, Thukral AD, Hwang WT, Solin LJ, Vapiwala N. Incidence and patterns of distant metastases for patients with early-stage breast cancer after breast conservation treatment. Clin Breast Cancer. 2013; 13: 88-94.

8. Ruiz A, Castro-Benitez C, Sebagh M, Giacchetti S, Castro-Santa E, Wicherts DA, et al. Repeat Hepatectomy for Breast Cancer Liver Metastases. Ann Surg Oncol. 2015; 22 Suppl 3: S1057-66.

9. Gerratana L, Fanotto V, Bonotto M, Bolzonello S, Minisini AM, Fasola G, et al. Pattern of metastasis and outcome in patients with breast cancer. Clin Exp Metastasis. 2015; 32: 125-33.

10. Geurts YM, Witteveen A, Bretveld R, Poortmans PM, Sonke GS, LJA S, et al. Patterns and predictors of first and subsequent recurrence in women with early breast cancer. Breast Cancer Res Treat. 2017; 165: 709-20.

11. Leone JP, Leone J, Zwenger AO, Iturbe J, Leone BA, Vallejo CT. Prognostic factors and survival according to tumour subtype in women presenting with breast cancer brain metastases at initial diagnosis. Eur J Cancer. 2017: 74: 17-25.

12. Legué LM, Simkens GA, Creemers GM, VEPP L, de Hingh IHJT. Synchronous peritoneal metastases of small bowel adenocarcinoma: Insights into an underexposed clinical phenomenon. Eur J Cancer. 2017; 87: 84-91.

13. Surveillance E RE(PRD(, National Cancer Institute D, Surveillance Research Program SSB, released April 2016 botN2s. http://www.seer.cancer.gov. Accessed August 20, 2017.

14. Pentheroudakis G, Fountzilas G, Bafaloukos D, Koutsoukou V, Pectasides D, Skarlos D, et al. Metastatic breast cancer with liver metastases: a registry analysis of clinicopathologic, management and outcome characteristics of 500 women. Breast Cancer Res Treat. 2006; 97: 237-44.

15. Duan XF, Dong NN, Zhang T, Li Q. The prognostic analysis of clinical breast cancer subtypes among patients with liver metastases from breast cancer. Int $\mathrm{J}$ Clin Oncol. 2013; 18: 26-32.

16. Metzger-Filho O, Sun Z, Viale G, Price KN, Crivellari D, Snyder RD, et al. Patterns of Recurrence and outcome according to breast cancer subtypes in lymph node-negative disease: results from international breast cancer study group trials VIII and IX. J Clin Oncol. 2013; 31: 3083-90.

17. Harrell JC, Prat A, Parker JS, Fan C, He X, Carey L, et al. Genomic analysis identifies unique signatures predictive of brain, lung, and liver relapse. Breast Cancer Res Treat. 2012; 132: 523-35.

18. Partridge AH, Hughes ME, Warner ET, Ottesen RA, Wong YN, Edge SB, et al. Subtype-Dependent Relationship Between Young Age at Diagnosis and Breast Cancer Survival. J Clin Oncol. 2016; 34: 3308-14.

19. Biganzoli E, Desmedt C, Fornili M, de Azambuja E, Cornez N, Ries F, et al. Recurrence dynamics of breast cancer according to baseline body mass index. Eur J Cancer. 2017; 87: 10-20.

20. Bartmann C, Diessner J, Blettner M, Häusler S, Janni W, Kreienberg R, et al. Factors influencing the development of visceral metastasis of breast cancer: A retrospective multi-center study. Breast. 2017; 31: 66-75.

21. Hsu CD, Wang X, Habif DV, Ma CX, Johnson KJ. Breast cancer stage variation and survival in association with insurance status and sociodemographic factors in US women 18 to 64 years old. Cancer. 2017; 123: 3125-31.

22. Jang N, Kwon HJ, Park MH, Kang SH, Bae YK. Prognostic Value of Tumor-Infiltrating Lymphocyte Density Assessed Using a Standardized Method Based on Molecular Subtypes and Adjuvant Chemotherapy in Invasive Breast Cancer. Ann Surg Oncol. 2018; 25: 937-46.

23. Vogel CL, Cobleigh MA, Tripathy D, Gutheil JC, Harris LN, Fehrenbacher L, et al. Efficacy and safety of trastuzumab as a single agent in first-line treatment of HER2-overexpressing metastatic breast cancer. J Clin Oncol. 2002; 20: 719-26.

24. Pagani O, Klingbiel D, Ruhstaller T, Nolè F, Eppenberger S, Oehlschlegel C, et al. Do all patients with advanced HER2 positive breast cancer need upfront-chemo when receiving trastuzumab? Randomized phase III trial SAKK 22/99. Ann Oncol. 2017; 28: 305-12.

25. Rossi M, Carioli G, Bonifazi M, Zambelli A, Franchi M, Moja L, et al. Trastuzumab for HER2+ metastatic breast cancer in clinical practice: Cardiotoxicity and overall survival. Eur J Cancer. 2016; 52: 41-9.

26. Foulkes WD, Smith IE, Reis-Filho JS. Triple-negative breast cancer. N Engl J Med. 2010; 363: 1938-48.

27. Bianchini G, Balko JM, Mayer IA, Sanders ME, Gianni L. Triple-negative breast cancer: challenges and opportunities of a heterogeneous disease. Nat Rev Clin Oncol. 2016; 13: 674-90.

28. Robson $\mathrm{M}$, et al. Olaparib for Metastatic Breast Cancer in Patients with a Germline BRCA Mutation. N Engl J Med. 2017; 377: 1700.

29. Nanda R, Chow LQ, Dees EC, Berger R, Gupta S, Geva R, et al. Pembrolizumab in Patients With Advanced Triple-Negative Breast Cancer: Phase Ib KEYNOTE-012 Study. J Clin Oncol. 2016; 34: 2460-7.

30. de Glas NA, Bastiaannet E, de Craen AJ, van de Velde CJ, Siesling S, Liefers GJ, et al. Survival of older patients with metastasised breast cancer lags behind despite evolving treatment strategies--a population-based study. Eur J Cancer. 2015; 51: 310-6.

31. Kumachev A, Trudeau ME, Chan KK. Associations among socioeconomic status, patterns of care and outcomes in breast cancer patients in a universal health care system: Ontario's experience. Cancer. 2016; 122: 893-8. 